\title{
ECOLOGÍA INTEGRAL Y PACTO EDUCATIVO GLOBAL. LA EDUCACIÓN INTEGRAL DEL PAPA FRANCISCO
}

\section{Integral ecology and global pact on education. The integral education of Pope Francisco}

\author{
Vítor Hugo Mendes \\ Santa Catarina (Brasil) \\ Correo-e: mendesvh@terra.com.br \\ Recibido: 29 de noviembre de 2020 \\ Envío a informantes: 3 de diciembre de 2020 \\ Aceptación definitiva: 22 de enero de 202I
}

Resumen: Tras el cónclave realizado en marzo de 20I3, Francisco se convirtió en el primer latinoamericano en ocupar el solio de Pedro. En noviembre de aquel año, él presentó su carta programática, la exhortación apostólica Evangelii gaudium, sobre el anuncio del Evangelio en el mundo actual. En mayo de 20I5, publicó la carta encíclica Laudato si', sobre el cuidado de la casa común. Según estimamos, este documento representa el culmen de la enseñanza social de Francisco, una propuesta de ecología integral que perfila un camino frente a la grave crisis ecológica que, a lo largo del siglo pasado, emergió como el gran reto global a ser enfrentado en el tercer milenio. Acompasada por esta reflexión emerge la cuestión educativa. Se trata de un ámbito temático que desde siempre ha merecido una especial atención de Jorge Mario Bergoglio. Como era de esperar, Francisco, además de reforzar la importancia de la educación, ha tratado de ir perfilando una propuesta educativa que, pari passu con su magisterio, adquirió una mayor relevancia a partir de su preocupación por el cuidado de la casa común. De ahí la necesidad de reconstruir el pacto educativo global. Con base en esto, en este trabajo, tratamos de presentar la educación integral de Francisco.

Palabras Clave: pacto educativo global; ecología integral; educación integral; desarrollo sostenible.

Aвstract: After the conclave held in March 2013, Francisco became the first Latin American to occupy the seat of Peter. In November of that year, he presented his pro- 
grammatic letter, the apostolic exhortation Evangelii gaudium, on the proclamation of the gospel in today's world. In May 2015, he published the encyclical letter Laudato si', on caring for our common home. As we estimate, this document represents the culmination of Francisco's social teaching, a proposal for integral ecology that outlines a path in the face of the serious ecological crisis that, throughout the last century, emerged as the great global challenge to be faced in the third millennium. Accompanied by this reflection, the educational question emerges. It is a thematic area that has always received special attention from Jorge Mario Bergoglio. As expected, Francisco, in addition to reinforcing the importance of education, has tried to outline an educational proposal that, pari pass $u$ with his teaching, acquired greater relevance from his concern with the care of the common home. Hence the need to rebuild the global educational pact. Based on this, in this work, we try to present Francisco's integral education.

KEY WORDs: Global pact on Education; integral ecology; integral education; sustainable development.

\section{Introducción}

$\mathrm{F}$ RANCISCO, OBISPo DE Roma y, por consiguiente, líder de la Iglesia católica, es el primer latinoamericano en ocupar el solio de Pedro. Es interesante notar que además de su encargo religioso, el primer Papa jesuita y el primero, también, de lengua española, se ha destacado en su pontificado por una particular apertura al diálogo con las más diversas instancias de la sociedad global. Con este estilo pontificio (pontifex, constructor de puentes), en diferentes oportunidades Francisco se ha propuesto generar procesos que tomaron por sorpresa a muchos. Sea porque trata de ir más allá de los límites teológico-pastorales de la institución eclesial que representa, sea porque entraña con sensibilidad franciscana, a partir de los pobres y de las periferias, los problemas más acuciantes de nuestra contemporaneidad. En poco más de ocho años, Francisco de Roma, quizás un retrato actual de Francesco d'Assisi, se ha convertido en una referencia ineludible en las búsquedas por construir una sociedad más justa y fraterna en la casa común.

Es oportuno señalar que, si bien las enseñanzas franciscanas del papa latinoamericano relucen particularmente ante la fuerza de sus incontables gestos de humanidad, que brotan naturalmente de su modo de vida sencillo y humilde, no menos significativo y enérgico es su magisterio escrito, una obra considerable tanto por la extensión como por su incisivo alcance temático. Además de volver, de manera innovadora, a los elementos más directamente vinculados a la dinámica vital del cristianismo (fe, santidad, familia, jóvenes, entre otros) y de la Iglesia (conversión pastoral, salida misionera, sinodalidad...), una pauta fundamental de su magisterio sigue siendo la problemática social. En este sentido, la radicalidad del pontífice al proponer un Evangelio sin glosas comenzó por recuperar el lugar social de la Iglesia: pobre para los pobres.

Tratando de rescatar esta trayectoria, el año pasado presentamos una tesis doctoral en la Universidad Pontificia de Salamanca que versó sobre la novedad y el aporte latinoamericano de Francisco a la Iglesia y a la sociedad (MENDEs, 2020). De ello se desprende un análisis bastante detallado de la carta encíclica Laudato si' (2015), sobre el cuidado de la casa común. Según estimamos, este documento representa el culmen de la enseñanza social del Papa latinoamericano, en definitiva, un programa de 
ECOLOGÍA INTEGRAL Y PACTO EDUCATIVO GLOBAL.

liberación integral a ser desarrollado en toda la extensión de la casa común. Aunque en esa línea fueron desarrolladas ulteriormente muchas otras iniciativas, y se publicaron documentos importantes (Querida Amazonia y Fratelli Tutti, por ejemplo), grosso modo se siguió profundizando el horizonte abierto por la ecología integral de Laudato si'. Esta perspectiva, brevemente, busca perfilar un camino frente a la grave crisis ecológica que, a lo largo del siglo pasado, emergió como el gran reto global a ser enfrentado en el tercer milenio.

Acompasada por esta reflexión, inevitable y transversalmente emerge la cuestión educativa. Como es ampliamente conocido, se trata de un ámbito temático que desde siempre ha merecido especial atención del profesor Bergoglio, primero como sacerdote y después como obispo y cardenal. Ahora, sin embargo, como era de esperar, Francisco además de reforzar la importancia de la educación, ha tratado de ir perfeccionando una propuesta educativa que, pari passu con su magisterio, adquirió una mayor relevancia a partir de su preocupación por el cuidado de la casa común.

Más allá de los aspectos educativos que han sido desarrollados en Laudato si', en octubre de 2020, por iniciativa de Francisco, se celebró en Roma, bajo la coordinación de la Congregación para la Educación Católica (en adelante CEC), un evento mundial en torno al tema Reconstruir el pacto educativo. Con ello se dio paso a un amplio proyecto que pretende realizarse en colaboración con diferentes instituciones de la Iglesia, religiones, organizaciones educativas y gubernamentales. De acuerdo con Francisco (2019b), «hoy más que nunca, es necesario unir los esfuerzos por una alianza educativa amplia para formar personas maduras, capaces de superar fragmentaciones y contraposiciones y reconstruir el tejido de las relaciones por una humanidad más fraterna».

Tomando en consideración estos elementos de carácter introductorio, a continuación tratamos de contextualizar este itinerario socioeclesial a fin de señalar lo que consideramos como la propuesta educativa de Francisco. Con esta intención, vamos a desarrollar dos aspectos puntuales de las enseñanzas de Francisco que consideramos que son complementarios: (I) Laudato si', la ecología integral y la educación; y (2) las distintas iniciativas que confluyen en el proyecto de Reconstruir el pacto educativo global. De ello emergen algunas pautas conclusivas.

\section{Laudato si', la ecología integral y la educación para una ciudadanía ecológica}

La elección de Francisco para liderar la Iglesia católica, en marzo de 20I3, fue un acontecimiento inusitado precedido por otro evento de gran repercusión histórica: la renuncia de Benedicto xvi (2005-2013), el papa alemán sucesor de Juan Pablo II (19782005). Por primera vez la Iglesia católica tenía un papa latinoamericano y por primera vez se reconocía en la Iglesia un papa emérito.

De cara a estos hechos tan extraordinarios, en noviembre de 2013 el cardenal argentino elegido sucesor de Pedro presentó su carta programática, la exhortación apostólica Evangelii gaudium, sobre el anuncio del Evangelio en el mundo actual, tratando de indicar una nueva etapa evangelizadora para la Iglesia ( $E G$, n. I). Después, en mayo de 2015 , se hizo pública la carta encíclica Laudato si', sobre el cuidado de la casa común, «una invitación urgente a un nuevo diálogo sobre el modo como estamos construyendo el futuro del planeta» $(L S, \mathrm{n}$. I4). De esa manera, dirigiéndose a la Iglesia y 
a la sociedad, Francisco fue instaurando una nueva dinámica pontificia con el fin de impulsar, como reitera en su última encíclica, Fratelli Tutti (2020), la fraternidad y la amistad social en la casa común.

La publicación de Laudato si', unos pocos meses antes de la 2I. ${ }^{a}$ Conferencia de las Naciones Unidas sobre el cambio climático, evento que se celebró en París, del 30 de noviembre al is de diciembre de 20I5, produjo una amplia repercusión en los medios de comunicación y generó una destacada atención crítica a la problemática ecológica. Además, era la primera vez que un papa dedicaba una encíclica a la problemática ecológica y lo hizo, como muchos han reconocido, no solo teniendo en cuenta los más recientes aportes de las ciencias, sino avanzando en proponer una ecología integral como parámetro indispensable para un desarrollo social sostenible ( $c f$. BRIGHENTI, 20I8).

Es interesante notar que el motivo que sirve de inspiración y da título a la encíclica, Laudato si' (mi' signore...), es una referencia explícita al famoso cántico espiritual de Francisco de Asís (II8I-I226): Alabado seas, mi Señor. Al mismo tiempo, Francesco, il poverello d'Assisi, es nada menos que el icono universal de la defensa de la ecología. De acuerdo con Francisco de Roma, al evocar la histórica trayectoria del santo italiano, «en él se advierte hasta qué punto son inseparables la preocupación por la naturaleza, la justicia con los pobres, el compromiso con la sociedad y la paz interior» ( $L S$, n. Io). En torno a esta imagen tan elocuente de una vida bienaventurada y que simboliza la búsqueda colectiva por fraternidad y una plena re-conciliación eco-lógica, el papa Francisco fue reuniendo muchos elementos necesarios a fin de dar forma actual y fundamento al necesario cuidado de la casa común.

En esta perspectiva no es menos llamativo el hecho de que, para dar sostenimiento y consecuencia a la reflexión propuesta, Laudato si' -sin decirlo expresamente- se ocupe en dar cabida a una metodología inductiva conocida como el método Ver, Juzgar, Actuar. Si bien esta metodología tiene su origen en la Juventud Obrera Católica (JOC), en Bélgica, esta tríada ha sido incorporada ulteriormente a la doctrina social de la Iglesia y, a partir de 1960, ha sido creativamente reapropiada de cara a la realidad latinoamericana, dando lugar, poco a poco, a cinco pasos: Ver-Juzgar-Actuar-Celebrar-Evaluar. Desde el comienzo, su importancia deriva, particularmente, de su creciente impacto en la formación de la conciencia crítica en las Comunidades Eclesiales de Base (СEB), en el impulso a la educación popular y, en su momento, por su reconocida contribución reflexiva en el amplio movimiento latinoamericano de liberación.

Aunque sin detenerse en explicitar los motivos que conllevaran esa opción metodológica, es un hecho que, con Laudato si', Francisco retomó con determinación cuatro de los cinco pasos latinoamericanos (Ver, Juzgar, Actuar y Celebrar) y los aplicó de manera muy exitosa, como se puede constatar en la organización de los capítulos de esta carta encíclica: (I) «Lo que le está pasando a nuestra casa»; (2) «El Evangelio de la creación»; (3) «Raíz humana de la crisis ecológica»; (4) «Una ecología integral»; (5) «Algunas líneas de orientación y acción»; y (6) «Educación y espiritualidad ecológica». Asimismo, a lo largo de ese itinerario sobresalen unos cuantos ejes transversales que, de modo crítico y propositivo, vuelven a la reflexión en distintos momentos:

La íntima relación entre los pobres y la fragilidad del planeta, la convicción de que en el mundo todo está conectado, la crítica al nuevo paradigma y a las formas de poder que derivan de la tecnología, la invitación a buscar otros modos de entender la economía y el 
progreso, el valor propio de cada criatura, el sentido humano de la ecología, la necesidad de debates sinceros y honestos, la grave responsabilidad de la política internacional y local, la cultura del descarte y la propuesta de un nuevo estilo de vida. ( $L S$, n. I6)

Como se puede percibir, el raciocinio que preside la encíclica trata de mostrar un examen objetivo de nuestra realidad, que no da lugar ni a simplificaciones ni a la desesperanza. En este sentido, como constata y advierte Laudato si, «entre los pobres más abandonados y maltratados, está nuestra oprimida y devastada tierra, que 'gime y sufre dolores de parto'» $(L S$, n. 2). Si bien se señala en el documento pontificio que «basta mirar la realidad con sinceridad para ver que hay un gran deterioro de nuestra casa común» ( $L S$, n. 6I) y todavía es necesario desarrollar una consciencia que nos lleve a percibir lo que realmente está ocurriendo, «la humanidad aún posee la capacidad de colaborar para [re]construir nuestra casa común» $(L S, \mathrm{n}$. I3). De ahí la incisiva convocatoria de Francisco a impulsar «una solidaridad universal nueva» en donde «todos podemos colaborar como instrumentos de Dios para el cuidado de la creación, cada uno desde su cultura, su experiencia, sus iniciativas y sus capacidades» (LS, n. I4).

Teniendo en cuenta esta realidad y los grandes retos que emergen de ella, el análisis de Laudato si' se orienta en contrastar el Evangelio de la creación, recordando que «la tierra nos precede y nos ha sido dada» (LS, n. 67), con lo que considera el predominio de un antropocentrismo desviado que, a su tiempo, ha dado «lugar a un estilo de vida desviado» ( $L S$, n. I22). Si, por un lado, en la creación todos somos deudores de «una realidad iluminada por el amor que nos convoca a una comunión universal» ( $L S$, n. 76$)$, generosa y gratuita; por otro lado, el papa hace notar que «el modo como la humanidad [...] ha asumido la tecnología y su desarrollo junto con un paradigma bomogéneo y unidimensional» (LS, n. I06) ha comprometido el auténtico progreso de la humanidad. Por su carácter instrumental, este paradigma tecnocrático, afirma la encíclica, «se ha vuelto tan dominante que es muy difícil prescindir de sus recursos, y más difícil todavía es utilizarlos sin ser dominados por su lógica» ( $L S$, n. Io8).

De acuerdo con Laudato si', superar este 'sistema' que, de modo especial, se fue imponiendo a lo largo de la modernidad a todo y a todos conlleva una responsabilidad ineludible y que compromete a cada uno a realizar esta tarea cada vez más urgente. En esta línea, «dado que todo está íntimamente relacionado, y que los problemas actuales requieren una mirada que tenga en cuenta todos los factores de la crisis mundial», lo que emerge en la encíclica es la proposición de «una ecología integral, que incorpore claramente las dimensiones humanas y sociales» (LS, n. I37). Es decir, ante los hechos, se enseña «que no hay dos crisis separadas, una ambiental y otra social, sino una sola y compleja crisis socio-ambiental» que exige «una aproximación integral para combatir la pobreza, para devolver la dignidad a los excluidos y simultáneamente para cuidar la naturaleza» ( $L S$, n. I39).

Para enfrentar esta situación socioambiental ampliamente examinada a la luz de la ecología integral y que precisa reorganizarse con miras a impulsar un desarrollo ecológico sostenible, los últimos capítulos de Laudato si', tratando de ser propositivos, indican líneas de acción que aspiran a servir de arranque para el cambio social que se necesita. En esta perspectiva, en el capítulo cinco, además de recordar que tenemos un solo mundo, se subraya que por esta razón estamos obligados a pensar un proyecto común (LS, n. I64). Es así como, con base en el diálogo, se hace hincapié en la necesidad de volver a re-unir política y representación política en torno al bien común, la 
política y la economía al servicio de la vida y de la plenitud humana, subrayando que ciencia y religión pueden interactuar y contribuir conjuntamente con miras a afrontar los grandes problemas de la humanidad.

Más allá de enunciar estos acuerdos posibles y necesarios para reorientar el rumbo de la política y de la economía, en el capítulo sexto se advierte la importancia de reconocer que, sobre todo, «la humanidad necesita cambiar». Es decir, se hace ver que es indispensable despertar a «la conciencia de un origen común, de una pertenencia mutua y de un futuro compartido por todos». Se considera que esto es lo que "permitiría el desarrollo de nuevas convicciones, actitudes y formas de vida» que efectivamente pueden cambiar el mundo. En torno a ello, señala la encíclica, se desprende «un gran desafío cultural, espiritual y educativo que supondrá largos procesos de regeneración» $(L S$, n. 202) a fin de resignificar la vida, recomponer el tejido social y recuperar la sustentabilidad de la casa común.

Aquí, de manera particular, se muestra imprescindible la educación en cuanto mediación que puede realizar un cambio en el estilo de vida y, por consiguiente, de la propia humanidad: «La conciencia de la gravedad de la crisis cultural y ecológica necesita traducirse en nuevos hábitos. [...] Por eso estamos ante un desafío educativo» (LS, n. 209). Esta comprensión crítica presume, evidentemente, que, así como la ecología, también la educación, para ser consecuente, ha de ser integral e integradora. De ahí, indicando un punto de apoyo decisivo, la insistencia en consolidar y ampliar los aportes ya realizados por la educación ambiental (cf. LS, n. 2Io) que, «llamada a crear una 'ciudadanía ecológica'» (LS, n. 2II), ha de educar para la adquisición de nuevos hábitos y lograr que se tornen efectivos como estilo de vida (cf. DOMINGo MORATALLA, 20I7).

Para llevar adelante este proyecto y para hacerlo tangible en la vida social, se considera necesario movilizar todos los ámbitos educativos (escuela, familia, medios de comunicación, catequesis, etc.). No obstante, además de matizar que «una buena educación escolar en la temprana edad coloca semillas que pueden producir efectos a lo largo de toda una vida», se resguarda un rol fundamental a la familia en lo que le corresponde. Como enseña la encíclica, «en la familia se cultivan los primeros hábitos de amor y cuidado de la vida [...]. La familia es el lugar de la formación integral» (LS, n. 213).

Finalmente, tras señalar la importante contribución que la política, las organizaciones de la sociedad y las Iglesias pueden realizar en términos de concientización de la población, también se recuerda que «si se quiere conseguir cambios profundos, hay que tener presente que los paradigmas de pensamiento realmente influyen en los comportamientos». En este sentido, tal como advierte Laudato si', «la educación será ineficaz y sus esfuerzos serán estériles si no procura también difundir un nuevo paradigma acerca del ser humano, la vida, la sociedad y la relación con la naturaleza. De otro modo, seguirá avanzando el paradigma consumista que se transmite por los medios de comunicación y a través de los eficaces engranajes del mercado» (LS, n. 215).

A grandes rasgos, concluido este breve itinerario, tenemos una panorámica de la manera como Francisco, con la encíclica Laudato si, fue dando forma a un pensamiento socioambiental que apuesta por el afianzamiento de una propuesta educativa. Como hemos dicho, tratando de sacar consecuencias de la ecología integral sugerida por el papa, él ha tenido otras iniciativas de gran impacto social. 
Una muestra de ello, directamente relacionada con Laudato si', fue la realización del Sínodo Panamazónico (2019). Este importante acontecimiento, que concluyó con la aprobación y divulgación del Documento Final (2019) y, luego, con la publicación de la Exhortación Postsinodal Querida Amazonia (2020), ha hecho un fuerte llamado sobre la grave problemática ecológica amazónica que, aunque siendo regional, no caben dudas, interesa a todo el planeta. Más recientemente se ha hecho pública Fratelli tutti (2020), una encíclica que, volviendo a referirse a Francisco de Asís, versa sobre la fraternidad y la amistad social. Publicada en el contexto de la pandemia por el Covid-r9, esta iniciativa pontificia no solo corrobora el necesario cuidado de la casa común, sino que compromete a todos con el logro de la libertad y la igualdad a partir de la fraternidad, una dimensión casi siempre olvidada en el mundo político-social, pero, también, en el ámbito educativo.

Teniendo presentes estos elementos que de forma innovadora han sido explicitados en el magisterio del papa latinoamericano, si bien, con Laudato si', ya hemos señalado la centralidad que ocupa la educación en sus enseñanzas, a continuación, vamos examinar, de manera más detenida, lo que viene madurando a la luz de la ecología integral en cuanto propuesta educativa. De lo dicho anteriormente, cabe recordar algo que estimamos fundamental afirmar, que, para Francisco, ecología y educación deben ser planteadas en su perspectiva integral.

\section{Reconstruir el pacto educativo global... hacia una educación integral}

De entrada cabe señalar que la educación siempre ha tenido una gran importancia en la Iglesia, bien sea como iniciación cristiana, formación catequética, litúrgico-sacramental, pastoral y teológica, o como educación escolar y universitaria. Hoy, sin embargo, se reconoce en ello una obra de gran alcance evangelizador y de cambio social ( $c f$. MENDES, 20I6). Además, como fue indicado, se trata de un aspecto fundamental del pontificado de Francisco que ha recibido particular atención en su labor pastoral. Siempre que se pronuncia, refiriéndose a la educación, en su discurso sobresale la 'urgencia' de una educación integral que sirva para la vida.

Grosso modo, el adjetivo integral que, cada vez con mayor frecuencia, aparece acoplado al término educación, parece servir para advertir críticamente de las 'insuficiencias' o 'reduccionismos' educativos que atascaron los ideales más elevados de formación humana, lo mismo que para reunir e indicar los elementos indispensables a tener en cuenta en la educación. De todas maneras, en la medida en que, a partir del siglo xIx, la educación se fue tornando un bien público, universal y gratuito, el carácter integral de la educación se ha tornado en una especie de reivindicación necesaria a fin de conseguir una educación efectivamente inclusiva de los derechos humanos y sociales y al servicio del bien común.

En la misión de la Iglesia, el carácter integral de la evangelización y, por consiguiente, de la educación, constituye una exigencia que se remite, invariablemente, a las enseñanzas de Jesús de Nazaret que, ulteriormente, afianzadas por un vasto emprendimiento bíblico-teológico, dieron origen a una multiforme 'pedagogía pastoral'. Paulo de Tarso, Clemente de Alejandría y san Agustín, entre otros, son nombres conocidos en la enunciación de esta trayectoria inicial de la educación cristiana. 
Aún debemos señalar que, no obstante que el Reinado de Dios y la salvación del mundo (salus mundi), anunciado por Jesucristo, haya sido excesivamente 'espiritualizado' y, contradictoriamente, vaciado de 'mundo', sigue implicando, tanto en el 'aquí' como en el 'más allá', un sentido radicalmente integral: que «todos tengan vida y la tengan en abundancia» (Jn Io,Io). De ahí emerge no solo una imagen virtuosa de discipulado, sino una razón teológica de la 'pedagogía pastoral' y de la 'educación integral' que se realiza mediante las obras pastorales y de asistencia social.

Obviamente esta perspectiva integral, en cuanto ideal educativo que se supone implícito en la educación católica, no se ha cumplido siempre plenamente; sin embargo, además de haber transmitido históricamente aportes pedagógicos relevantes a la educación, sigue siendo una obra considerable por su capilaridad y su alcance social, como se puede visualizar en los datos que se presentan a continuación (ver Tabla I y Tabla 2).

TABLA I. La Iglesia católica en números (FIDES/2020)

\begin{tabular}{|l|c|c|}
\hline \multicolumn{2}{|c|}{ ASPECTOS GENERALES } & OBRAS DE ASISTENCIA \\
\hline Población total & 7.496 .394 .000 & Hospitales \\
\hline Católicos & I.328.993.000 & Dispensarios \\
\hline Hab./sacerdotes & $\mathrm{I} 4.638$ & Leproserías \\
\hline $\begin{array}{l}\text { Circunscripciones } \\
\text { eclesiásticas }\end{array}$ & 3.025 & $\begin{array}{c}\text { Casa para ancianos, enfermos crónicos, } \\
\text { discapacitados }\end{array}$ \\
\hline Obispos & 5.377 & Orfanatos \\
\hline Sacerdotes & 414.065 & Consultorios matrimoniales \\
\hline Diáconos & 47.504 & Jardines de infancia \\
\hline Religiosos/as & 692.602 & Centros de educación o reeducación \\
\hline Misioneros laicos & 376.188 & Otras instituciones \\
\hline Catequistas & 3.076 .624 & Ioo.I64 \\
\hline Seminar./Menores & & II5.880 \\
\hline Semin./Mayores & \multicolumn{2}{|c|}{} \\
\hline
\end{tabular}

TABLA 2. La educación católica en el mundo (FIDES/2020)

\begin{tabular}{|l|c|c|}
\hline \multicolumn{1}{|c|}{ NIVELES } & INSTITUCIONES & ESTUDIANTES \\
\hline Escuelas infantiles & 73.164 & 7.376 .858 \\
\hline Escuelas primarias & I03.146 & 35.011 .999 \\
\hline Institutos de secundaria & $49.54 \mathrm{I}$ & 19.307 .298 \\
\hline Escuelas superiores & - & 2.251 .600 \\
\hline Estudiantes universitarios & - & 3.707 .559 \\
\hline Total & $225.85 \mathrm{I}$ & 67.655 .314 \\
\hline
\end{tabular}


Aun considerando que estos aspectos indicados merecerían un mayor análisis, explicitación y discernimiento, parece justificable que este no es el momento para hacerlo en profundidad. De todas formas, dada la dimensión y el alcance de todo este emprendimiento, no deja de sorprender que Francisco, más allá de lo que se hace, no solo sigue pidiendo un mayor empeño pastoral y educativo de la Iglesia en el cuidado de la casa común, sino que también se ha puesto a dialogar con toda la sociedad sobre la necesidad de reconstruir el pacto educativo global.

Vale la pena recordar que, para Francisco, la educación representa un interés antiguo que, además, él ha ejercido en diferentes encargos con creatividad y pasión ( $c f$. SPADARO, 20I8). Como arzobispo de Buenos Aires, en el mismo año en que fue elevado a cardenal de la Iglesia (200I), Jorge Mario Bergoglio supo dar importancia y apoyo a una iniciativa que puso en marcha lo que se denominó Escuela de Vecinos. La propuesta, inicialmente encabezada por el profesor José María del Corral y un grupo de educadores, se dirigía a las escuelas católicas y no católicas y de realidades diversas en la capital bonaerense, y tenía como objetivo acercarse a los estudiantes para establecer un diálogo sobre la educación a partir de sus necesidades. De esa manera, se buscó problematizar con ellos diferentes impases educativos, teniendo como perspectiva ejercitar la ciudadanía y trabajar por el bien común. Como consecuencia de ese movimiento, en 2006 fue aprobado el programa Buenos Aires, cindad educativa (Ley 2169), que buscaría impulsar la educación en el encuentro y en el diálogo (cf. PEREGO, 2020).

Cuando el cardenal Bergoglio fue elegido papa, la exitosa experiencia fue llevada al Vaticano y, en el 20I3, bajo el nombre Scholas Occurrentes, se transformó en una Organización Internacional de Derecho Pontificio ( $c f$. EDITORIAL, 20I7). Con sede en diferentes países, actualmente la organización se encuentra presente en r9o países, siendo una red que congrega a más de 400.000 centros educativos. Conforme está indicado en su página web (2020), Scholas fue soñado «como la posibilidad de dar una respuesta concreta al llamado de esta época, confiriéndole la tarea de educar en la apertura al otro, en la escucha que al reunir los pedazos de un mundo atomizado y vacío de sentido, comience a crear una nueva cultura: la cultura del encuentro».

Posteriormente, en 2015, con ocasión del 50. ${ }^{\circ}$ aniversario de la Declaración del Concilio Vaticano II Gravissimum educationis (1965), sobre la educación cristiana, y del $25^{\circ}$ aniversario de la Constitución Apostólica Ex corde ecclesiae (1990), sobre las universidades católicas, se organizó en Roma un importante evento mundial de educación católica. Después de una cuidadosa preparación, del i8 al 2i de noviembre, con la participación de representantes de todo el mundo, se realizó el Congreso Educar boy y mañana. Una pasión que se renueva ( $c f$. CEC, 20I4). A fin de profundizar en los desafíos presentes de la educación y de animar la tarea de los educadores y educadoras, se dio acogida y destaque a los propósitos educativos de Francisco. En octubre del mismo año, a pedido de la Congregación de Educación Católica, Francisco creó la Fundación Gravissimum Educationis con el fin de estimular la colaboración entre las instituciones escolares y universitarias.

En 2017, una vez más, ahora con motivo del 50..$^{\circ}$ aniversario de la encíclica $\mathrm{Po}_{0}$ pulorum progresio (1967), que versa sobre la necesidad de promover el desarrollo de los pueblos, la Congregación de Educación Católica, tratando de dar recepción a las enseñanzas de Francisco, hizo público el documento Educar al bumanismo solidario para construir una civilización del amor (CEC, 20I7). Señalando la necesidad de buma- 
ECOLOGÍA INTEGRAL Y PACTO EDUCATIVO GLOBAL.

LA EDUCACIÓN INTEGRAL DEL PAPA FRANCISCO

VÍTOR HUGO MENDES

nizar la educación, el documento pondera que eso «significa poner a la persona al centro de la educación, en un marco de relaciones que constituyen una comunidad viva, interdependiente, unida a un destino común. De este modo se cualifica el humanismo solidario. Humanizar la educación significa, también, reconocer que es necesario actualizar el pacto educativo entre las generaciones» (CEC, 2017, nn. 8-9).

Además de todas estas iniciativas llevadas a cabo con la activa participación de Francisco, las frecuentes intervenciones que el papa ha hecho a propósito de la educación convergen en señalar y discernir los desafíos del presente, no obstante que abriendo caminos y posibilidades que permitan seguir adelante. Algo de esto puede ser visto, por ejemplo, cuando se dirige a los jóvenes en la exhortación postsinodal Christus vivit (2019). Después de acercarse a las distintas situaciones que ellos viven, refiriéndose a la educación católica, apunta como indispensable la «renovación y relanzamiento de las escuelas y universidades 'en salida' misionera» a fin de dar cabida a los anhelos juveniles. Para ello presenta los criterios que deberán ser tomados en consideración: «La experiencia del kerygma, el diálogo a todos los niveles, la interdisciplinariedad y la transdisciplinariedad, el fomento de la cultura del encuentro, la urgente necesidad de 'crear redes' y la opción por los últimos, por aquellos que la sociedad descarta y desecha». Además, agrega, «la capacidad de integrar los saberes de la cabeza, el corazón y las manos» (FRANCISCO, 2019, n. 222).

A partir de esta breve exposición que trata de contextualizar la intensa trayectoria de Francisco respecto a la educación, se pueden entrever los motivos en donde se arraiga el propósito de reconstruir el pacto educativo global, así como la tarea que se ha de poner en marcha. Como él mismo ha indicado al lanzar la propuesta, dirigiéndose a educadores, dirigentes políticos y sociales, y a los jóvenes, se trata de una invitación «a promover juntos y a impulsar, a través de un pacto educativo común, aquellas dinámicas que dan sentido a la historia y la transforman de modo positivo» (2019b).

El evento principal, planeado y convocado para realizarse inicialmente en el mes de mayo, debido a la pandemia Covid-ig finalmente fue celebrado el is de octubre de 2020, en la Universidad Lateranense, en Roma, abierto a la participación virtual. Cabe recordar que el intrumentum laboris (CEC, 20I9) dado a conocer previamente generó un amplio debate y muchas iniciativas que estuvieron dedicadas a preparar y a impulsar el evento en todos los ámbitos posibles (local, nacional, regional...).

Puede decirse que este programa, en particular, recoge de modo completo los diferentes aspectos de la problemática educativa que Francisco venía advirtiendo. Sin embargo, ahora, se formula una propuesta osada, en diálogo con la sociedad, con miras a refundar el pacto educativo global, implicando la ecología integral.

De cara a esto, lo que dijo Francisco (2020) en la apertura del evento resulta de suma importancia para indicar el horizonte educativo integral que conlleva este compromiso.

Como era de esperarse el punto de partida fue la pandemia, su impacto en los sistemas educativos mundiales y la 'catástrofe educativa' que ha generado. Esta dramática realidad, indica Francisco, hace percibir que «la crisis que atravesamos es una crisis global, que no se puede reducir ni limitar a un único ámbito o sector. Es general. El Covid ha hecho posible reconocer de forma global que lo que está en crisis es nuestro modo de entender la realidad y de relacionarnos». Toda esta situación, señala el mensaje, «más allá de las recetas simplistas o de los vanos optimismos», muestra 
con mayor énfasis la importancia de la educación. En definitiva, advierte, «educar es siempre un acto de esperanza que invita a la coparticipación y a la transformación de la lógica estéril y paralizante de la indiferencia en otra lógica distinta, capaz de acoger nuestra pertenencia común».

Con base en esto, la educación es tomada como «una de las formas más efectivas de humanizar el mundo y la historia» y es indicada como "el antídoto natural de la cultura individualista» vigente. No obstante, para ser efectiva, esta educación conlleva un «amor y responsabilidad que se transmite en el tiempo, de generación en generación», exige «un nuevo periodo de compromiso educativo, que involucre a todos los componentes de la sociedad». Además, se trata de «escuchar el grito de las nuevas generaciones, que manifiesta la necesidad y, al mismo tiempo, la oportunidad estimulante de un renovado camino educativo, que no mire para otro lado, favoreciendo graves injusticias sociales, violaciones de derechos, grandes pobrezas y exclusiones humanas». Esto implica, por tanto, plantear un itinerario integral que incluye afrontar «el 'sufrimiento' de nuestro planeta, provocado por una explotación sin inteligencia y sin corazón, que ha generado una grave crisis medioambiental y climática».

Teniendo en cuenta esto, el pacto educativo «para y con las generaciones más jóvenes» pretende que «la formación de personas maduras» sea una responsabilidad que involucre a todos (familias, comunidades, escuelas y universidades, instituciones, religiones, gobernantes). Para ello será necesario «superar las excesivas simplificaciones aplanadas sobre la utilidad, sobre el resultado -estandarizado-, sobre la funcionalidad y la burocracia que confunden educación con instrucción y terminan destruyendo nuestras culturas; más bien se nos pide que busquemos una cultura integral, participativa y multifacética». En definitiva, señala Francisco, «el valor de nuestras prácticas educativas no se medirá simplemente por haber superado pruebas estandarizadas, sino por la capacidad de incidir en el corazón de una sociedad y dar nacimiento a una nueva cultura. Un mundo diferente es posible y requiere que aprendamos a construirlo, y esto involucra a toda nuestra humanidad, tanto personal como comunitaria».

A fin de dotar de eficacia estos propósitos, Francisco propone siete aspectos a tenerse en cuenta: (I) la centralidad de la persona en el proceso educativo; (2) la escucha de los estudiantes; (3) la plena participación de las niñas y las jóvenes en la educación; (4) la insustituible tarea educadora de la familia; (5) la mirada inclusiva que tome en cuenta a los vulnerables y marginados; (6) hacer de la economía, la política, el crecimiento y el progreso un servicio a la vida; y (7) el cuidado de la casa común.

En términos de continuidad, el proceso iniciado con el pacto educativo seguirá siendo articulado en torno a cuatro ejes temáticos: a) dignidad bumana y derechos; b) ecología integral; c) paz y ciudadania; y d) solidaridad y desarrollo. Trabajos ya en desarrollo, cada uno bajo la coordinación de instituciones universitarias en Italia (2), en Colombia (I) y en Estados Unidos (I), fueron organizados de modo que, además de la adhesión al pacto educativo, los interesados en contribuir también puedan incorporarse según el interés por los temas propuestos.

\section{Conclusión}

Al finalizar este itinerario quizás una primera conclusión posible es que Francisco, el primer latinoamericano elegido sucesor de Pedro, por cuenta de su labor educativa, 
ya puede ser considerado como el Papa de la educación. Además, se hace cada vez más evidente que este componente transversal de su magisterio social se ha vuelto un canal imprescindible de diálogo y de colaboración con la sociedad en todo el mundo.

Como hemos visto, para Francisco el cuidado de la casa común (Laudato si') es una tarea urgente que reúne y responsabiliza a toda la humanidad y, en la misma medida, exige de todos un renovado empeño educativo. De ese modo, la ecología integral y el pacto educativo global son dos caras de una misma moneda.

Este nuevo horizonte educativo propuesto y desarrollado por Francisco ha sido expresado en una hermosa imagen tomada de un proverbio africano: «Para educar a un niño se necesita una aldea entera'. Por lo tanto -agrega él- debemos construir esta aldea como condición para educar» (FRANCISCO, 2019).

Tratando de eludir cualquier tipo de romanticismo, esta reivindicación activa que hace Francisco nos remite efectivamente a la política, a la economía, a la sociedad y, no en último lugar, a la ciudadanía. De ello se deriva la conclusión ineludible de que necesitamos una educación integral para cambiar el rumbo de la civilización en el planeta.

Ahora bien, según la enseñanza franciscana del papa latinoamericano, la educación, para ser integral, conlleva una ruta de aprendizaje que ha de ser radicalmente integradora, a fin de recrear la alianza entre la humanidad y el ambiente. En sus propias palabras, una «tal inversión formativa, basada en una red de relaciones humanas y abiertas, debe garantizar el acceso de todos a una educación de calidad, a la altura de la dignidad de la persona humana y de su vocación a la fraternidad» (FRANCISCO, 2020).

\section{Bibliografía}

Agencia Fides. (2020). Las estatísticas de la Iglesia Católica 2020. Recuperado el I3 de noviembre de 2020, de http://www.fides.org/es/stats.

Brighenti, A. (2018). A Laudato Si' no pensamento social da Igreja. Da ecologia ambiental à ecologia integral. São Paulo: Paulinas.

Congregación para la Educación Católica. (1994). Educar hoy y mañana. Una pasión que se renueva. Instrumentum laboris. Recuperado el 29 de octubre de 2020, de http:// www.vatican.va/roman_curia/congregations/ccatheduc/documents/rc_con_ccatheduc_ doc_20140407_educare-oggi-e-domani_sp.html.

CONGREGACIÓN PARA LA EDUCACIÓN CATÓLICA. (20I7). Educar al humanismo solidario. Recuperado el 29 de octubre de 2020, de http://www.vatican.va/roman_curia/congregations/ ccatheduc/documents/rc_con_ccatheduc_doc_20170416_educare-umanesimo-solidale_ sp.html.

Congregación para la Educación Católica. (2020). Pacto Educativo Global. Intrumentum laboris. Recuperado el 29 de octubre de 2020, de https://www.educationglobalcompact.org/resources/Risorse/instrumentum-laboris-sp.pdf.

Domingo Moratalla, A. (2017). Condición humana y ecología integral: horizontes educativos para una ciudadanía integral. Madrid: PPC/AGAPEA.

EDITORIAL. (2017). Scholas Occurrentes: la cultura del encuentro del Papa Francisco. Razón y $\mathrm{Fe}, \mathrm{I433}, 259-264$.

Francisco. (20I5). Landato si' sobre el cuidado de la casa común. Recuperado el io de octubre de 2020, de http://w2.vatican.va/content/francesco/es/encyclicals/documents/papa-francesco_20I50524_enciclica-laudato-si.html. 
Francisco. (2018). Discurso a los miembros de la Fundación Gravissimum Educationis. Recuperado el ro de noviembre de 2020 , de http://www.vatican.va/content/francesco/es/speeches/20I8/june/documents/papa-francesco_20I80625_gravissimum-educationis.html.

Francisco. (2019a). Christus vivit, a los jóvenes. Recuperado el 30 de octubre de 2020, de http://www.vatican.va/content/francesco/es/apost_exhortations/documents/papa-francesco_esortazione-ap_20190325_christus-vivit.html.

Francisco. (2019b). Mensaje para el lanzamiento del Pacto Educativo Global. Recuperado el I2 de noviembre de 2020, de http:/www.vatican.va/content/francesco/es/messages/ pont-messages/2019/documents/papa-francesco_20190912_messaggio-patto-educativo. html.

Francisco. (2020). Videomensaje con ocasión del encuentro promovido y organizado por la Congregación para la Educación Católica: Pacto Educativo Global. Recuperado el 8 de noviembre de 2020, de http://www.vatican.va/content/francesco/es/messages/pont-messages/2020/documents/papa-francesco_2020IOI5_videomessaggio-global-compact.html.

Juan Pablo ir. (1990). Ex corde ecclesiae, sobre las universidades católicas. Recuperado el 30 de octubre de 2020, de https://w2.vatican.va/content/john-paul-ii/es/apost_constitutions/ documents/hf_jp-ii_apc_I5081990_ex-corde-ecclesiae.html.

LeY 2169 (2006). Buenos Aires: Ciudad Educativa. Recuperado el I3 de noviembre de 2020, de http://www2.cedom.gob.ar/es/legislacion/normas/leyes/ley2169.html.

Mendes, V. H. (2016). Escola em saída... Propostas educativas para a Escola Católica na América. Educación Hoy, 203, 66-83.

Mendes, V. H. (2020). Liberación, un balance bistórico bajo el influjo de Aparecida y Laudato si. El aporte latinoamericano de Francisco. Tesis doctoral no publicada. Universidad Pontificia de Salamanca. Salamanca.

PABlo vi. (1965). Gravissimum educationis, sobre la educación cristiana. Recuperado el is de noviembre de 2020 , de http://www.vatican.va/archive/hist_councils/ii_vatican_council/ documents/vat-ii_decl_19651028_gravissimum-educationis_po.html.

Perego, P. (2020). Educación. Con el pacto en el ADN. Entrevista José María de Corral, Fundador de Scholas Occurrentes. Recuperado el 20 de noviembre de 2020, de https://espanol. clonline.org/noticias/iglesia/2020/10/13/educacion-con-ese-pacto-en-el-adn.

Scholas. (2020). Homepage Scholas Occurrentes. Recuperado el 9 de noviembre de 2020, de https://www.scholasoccurrentes.org/sobre-scholas/.

Spadaro, A. (2018). Sette pilastri dell'educazione secondo J. M. Bergoglio. La Civiltà Cattolica, 4037, 343-357. 
